\title{
FOTONİK KRİSTALLERDE TÜMYÖNLÜ BANT ARALIĞININ İNCELENMESİ
}

\author{
Onur ERKAN*, Serkan ŞIMŞEK
}

İstanbul Teknik Üniversitesi, Elektrik-Elektronik Mühendisliği Fakültesi, Elektronik ve Haberleşme Mühendisliği Bölümü, İstanbul, Türkiye

\begin{tabular}{ll}
\hline Anahtar Kelimeler & Öz \\
\hline Periyodik Yapılar, & Kablolu ve kablosuz ağ teknolojilerinde veri kullanım oranının artması taşıyıcı \\
Fotonik Kristaller, & ortamdaki bant genişliklerinin daha etkin kullanıması gerekliliğini ortaya çıkarmıştır. \\
Tümyönlü Yansıtıcılar, & Gelişen malzeme teknolojisi sayesinde nanometre boyutlarında düşük güçle çalışan \\
AFGSM Yöntemi. & ve optik spektrumun verimli kullanılmasını sağlayan bileşenlerin tasarlanması \\
& mümkün hale gelmiştir. Bu çalışmada optik frekans bölgesindeki uygulamalarda \\
& kullanılan geliş açısı ve kutuplanmadan bağımsız tümyönlü yansıtıcı bileşeninin \\
& analiz ve tasarımı yapılmıştır. Tümyönlü yansıtıcının bant kenar frekanslarının \\
& belirlenmesinde, bilinen sayısal yöntemlere alternatif olarak daha hızlı ve yüksek \\
& doğrulukta sonuç veren genelleştirilmiş saçılma matrisi yardımcı fonksiyonları \\
& (AFGSM) yöntemi kullanılmıştır. Önerilen alternatif yöntem ile periyodiklik koşulu \\
& altında istenen tümyönlü yansıtıcı parametrelerini sağlayan fotonik kristalli \\
& dielektrik malzemeler uygun şekilde seçilmiş (Te, Ta $\mathrm{O}_{5}$, TiO ${ }_{2}$ ) ve elde edilen sonuçlar \\
& bilgisayar benzetimleri ile doğrulanmıştır. Tasarımı yapılan yansıtıcı, optik dalgaboyu \\
& bölgesinde \%56.63'lük tümyönlü bağll bant genişliği (ORB) değerine sahip, 924 nm - \\
& 1654 nm aralığında tümyönlü fotonik durdurma bandı (OBG) sağlamaktadır.
\end{tabular}

\section{INVESTIGATION OF OMNIDIRECTIONAL BANDGAPS IN PHOTONIC CRYSTALS}

\section{Keywords \\ Periodic Structures, \\ Photonic Crystals, \\ Omnidirectional Reflectors, AFGSM Method.}

\begin{abstract}
Rapidly increasing data usage rates in fixed and wireless technologies encouraged the researches to find alternative ways of using limited bandwidth in carrier medium more efficiently. Recent developments in material science, particularly in nanometer scale, allowed engineers to design low power components that can ensure efficient use of optical spectrum. In this study, we designed an omnidirectional reflector that can be used as an optical component without any dependency on polarization or angle of incidence. Band edge frequencies of omnidirectional reflector are determined by employing auxiliary functions of generalized scattering matrix (AFGSM) method which provides faster and accurate estimates in comparison to conventional methods existing in the literature. Using the proposed method proper photonic crystal structures ( $\mathrm{Te}, \mathrm{Ta}_{2} \mathrm{O}_{5}, \mathrm{TiO}_{2}$ ) are selected according to given design objective while satisfying the periodicity condition. Computer simulation results are given for verification. The designed reflector provides an omnidirectional relative bandwidth (ORB) value of $56.63 \%$ with an omnidirectional photonic bandgap (OBG) in the range of $924 \mathrm{~nm}$ to $1654 \mathrm{~nm}$ in optical wavelength region.
\end{abstract}

\section{Alıntı / Cite}

Erkan, O., Şimșek, S., (2019). Fotonik Kristallerde Tümyönlü Bant Aralığının İncelenmesi, Mühendislik Bilimleri ve Tasarım Dergisi, 7(4), 744-750.

Yazar Kimliği / Author ID (ORCID Number)

O. Erkan, 0000-0002-2930-1486

S. Şimşek, 0000-0003-0964-2176

\author{
Makale Süreci / Article Process \\ Başvuru Tarihi / Submission Date \\ Revizyon Tarihi / Revision Date \\ Kabul Tarihi / Accepted Date \\ Yayım Tarihi / Published Date
}

\begin{tabular}{|l}
08.01 .2019 \\
08.05 .2019 \\
20.05 .2019 \\
19.12 .2019
\end{tabular}

\footnotetext{
* ilgili yazar / Corresponding author: erkanonu@itu.edu.tr, +90-212-285-3624
} 


\section{Giriş}

Elektromanyetik dalgaların dielektrik sabiti periyodik olarak değişen yapılarda propagasyonu, belirli frekans aralı̆̆ında ve belirli doğrultuda kontrol edilebilmektedir. Bu teori ilk olarak 19. yüzyıl sonlarında Rayleigh ve Brillouin tarafından yapılan çalışmalarda incelenmiştir. Bu çalışmalarda periyodik yapıların ışığın geliş açısına bağlı olarak değișen bir band aralığına sahip olduğu ortaya konulmuştur. 1987 yllında Eli Yablonovitch fotonik kristaller kullanarak durdurma bantlarını incelediği deneysel araştırmalarını yayınlamıştır. Fotonik kristallerin güçlü yansıma gösterdiği, elektromanyetik dalgaların iletiminin engellendiği frekans aralığı "fotonik bant aralığı" (PBG: photonic bandgap) olarak adlandırılmaktadır (Joannopoulos vd., 2008). Bu fenomen kullanılarak fotonik kristaller ve uygulamaları son yıllarda birçok bilimsel çalışma ve mühendislik uygulama alanına konu olmuștur. $\mathrm{Bu}$ uygulamalar arasında yer alan bileșenlerden bazıları dalga kılavuzları, ayırıcılar (splitters), dağılmış geribeslemeli lazerler, dielektrik fabry-perot filtreler, ayarlanabilir polarizörler, optik fiber yapılar, dielektrik yansıtıcılar, demet bölücüler ve optik filtrelerdir.

Fotonik kristallerin propagasyon karakteristiği, yapının iletim-durdurma bant diyagramının çıkarılması ile elde edilebilmektedir. Fiziksel ve elektriksel özellikleri seçilmiş (veya belirlenmiş) bir fotonik kristalin fotonik durdurma bandı sadece belli bir frekans, geliş açısı ve kutuplanma için geçerlidir. Çalışma frekansı, geliş açısı ve kutuplanma değiştirildiğinde fotonik durdurma bandı farklı spektral bölgelerde oluşabilir veya durdurma bandı oluşmayabilir. Fotonik kristallerde malzeme dielektrik özellikleri ve katman kalınlıklarının uygun olarak seçilmesi sonucu istenen frekans bölgesinde, kutuplanma ve geliş açısından bağımsız tümyönlü durdurma bant aralığı (OBG: omnidirectional bandgap) elde edilebilmektedir. Fink vd., (1998) yılında yapmış olduğu çalışmada çeyrek dalga uzunluğunda katmanlar (quarter-wave stack) ile elde edilen tümyönlü yansitıcının durdurma bantlarını incelemiştir.

Tümyönlü yansıtıcılar veya diğer optik bileşenler tasarlanırken fabrikasyon sürecine geçilmeden önce periyodik yapının ideale yakın dizayn edilebilmesi için birden fazla sayısal modelleme yapılması gerekmektedir. Bu sebeple hızlı ve doğru sayısal benzetim ile fotonik kristal tasarımı çok büyük önem teşkil etmektedir. Fotonik bant aralıklarının hesaplanmasında düzlem dalga açılım yöntemi (PWE) başta olmak üzere, zamanda sonlu farklar yöntemi (FDTD), transfer matrisi metodu (TMM), sonlu elemanlar metodu (FEM) sıklıkla kullanılan yöntemlerden başlıcalarıdır. Birçok elektromanyetik problemin çözümünde kullanılan bu yöntemler ile analiz yapmak mümkün olmasına rağmen problemin özdeğer denklemine indirgenmesi ve istenen frekans aralığında özdeğer denkleminin çözümünün aranması hesap uzayını genişletmektedir. $\mathrm{Bu}$ noktada periyodik yapının özdeğer denkleminin çözümüne gerek kalmadan bant kenar frekanslarının hesaplanabilmesinin problemin çözümüne büyük kolaylık getireceği aşikardır.

Literatürde kayıpsız periyodik yapılardaki birim hücrenin genelleştirilmiş saçılma matrisi için ortaya konan sakınım ilişkisi vasıtasıyla, özdeğer denkleminin çözülmesine gerek kalmadan iletimdurdurma bant geçiş frekanslarının tespit edilebildiği ispatlanmıştır (Şimşek ve Topuz, 2007). Devam eden çalıșmalarda, genelleștirilmiş saçılma matrisi yardımcı fonksiyonları yöntemi (AFGSM) kullanılarak periyodik yapıların bant geçiş frekansları analitik yardımcı fonksiyonlar ile sayısal olarak doğru ve verimli bir şekilde tespit edilmiştir (Erkan vd., 2018; Ertay ve Şimşek, 2018).

Aynı zamanda bu çalışmada, yöntemin tümyönlü bant aralıklarının belirlenmesinde ve yansitıcı tasarımında etkin bir şekilde kullanılabildiği belirtilmiştir. $\mathrm{Bu}$ yönüyle, mikrodalga uygulamalarında sıklıkla kullanılan saçılma parametrelerinin hesaplamasına dayanan yaklaşımın optik bölgede uygulanmasının mümkün olduğu gösterilmiştir.

\section{Bilimsel Yazın Taraması}

Günümüzde mobil ve sabit haberleşme şebekelerinin altyapısını oluşturan fiber optik haberleșme sistemleriyle uzak mesafelere yüksek kapasiteli veri aktarımı optik spektrumda bant genişliklerinin etkin kullanılması ile mümkün olmaktadır. Gelişen malzeme teknolojisi ile düşük güçle çalışan, nanometre boyutlarında entegre elemanlar ile optik seviyede anahtarlama sağlanabilmektedir. Optik anahtarlama modüllerinin yanısıra hareketli mikro aynaların kullanıldığı MEM (mikro-elektro mekanik) teknolojisinin uygulandığı optiksel çapraz bağlayıcılar (OCX) (Notomi 2005), yoğun dalgaboyu bölmeli sayısal çoklayıcılar (DWDM) (Wosinski vd., 2009) gibi temelde optik filtre yapısında çalışan telekomünikasyon elemanları fotonik kristaller ile gerçeklenebilmektedir. Kablosuz ağ teknolojilerinde kullanılan anten uygulama örneklerinde fotonik kristallerin kullanılması sonucu yüzey dalgaları sönümlendirildiği için anten kazancını ve anten yönlülüğünü artırdığı gösterilmiştir (Sharma vd., 2008; Liang vd., 2009). Kablolu haberleşme sistemlerinde ise dar bandgenişliğine sahip kanallar kullanılarak frekans spektrumunu etkin bir șekilde kullanabilmek hedeflenmektedir. Bunu sağlayabilmek için keskin geçişlere sahip filtre yapısı tasarlanarak yan kanallara girişimin en aza indirgenmesi gerekmektedir. Fotonik kristaller optik entegre teknolojilerinde istenen bu özelliklerde tasarlanarak ideale yakın optik filtreler elde 
edilebilmektedir (Banaei vd., 2014; Prather vd., 2009).

Optik bileşenlerin modellenmesinde belli bir frekans bandında bütün geliş açıları ve kutuplanmalar için geçerli olan bir durdurma bandının tasarlanması hedeflenmektedir. $\mathrm{Bu}$ durumda oluşan fotonik durdurma bandı tümyönlü fotonik durdurma bandı olarak adlandırılmaktadır. Kim vd. (2002)'de çeyrekdalga uzunluğunda (QWS) dielektrik tabakalardan oluşan geniş bir tümyönlü yansıtıcı tasarımı için yüksek kırılma indisinin 2.26'dan büyük, düșük kırılma indisinin ise yaklaşık olarak 1.5 seçilmesi gerektiğini ortaya koymuștur. Southwell'in (1999)'da yaptığı çalıșmada ise düșük kırılma indisli malzemenin kırılma indisinin 1.45 civarında seçilmesinin, yüksek kırılma indisinin seçiminden bağımsız olarak geniş tümyönlü yansıtıcı elde etmek için yeterli olduğu ifade edilmiştir. Srivastava vd., (2007)'de fuleren film tabakalar kullanarak bir boyutlu fotonik kristallerde tümyönlü yansıtma bandı tasarımı yapmıştır. Chigrin (1998)'de tümyönlü yansıtıcı özellikleri elde edebilmek için bir boyutlu fotonik kristallerin kullanımının yeterli olduğunu gösteren çalışmayı yayınlamıştır. Haas (2006) ve Hwang'ın (2007)'de yaptığı çalışmalarda ise iki boyutlu tümyönlü durdurma bölgelerinin elde edilmesi incelenmiştir. Chen (2011)'de yaptığl çalışmalarında iki boyutlu fotonik kristal tümyönlü yansıtıcılar ile dalga klavuzlarının tasarımına ilişkin örnekler sunmuştur.

$\mathrm{Bu}$ çalışmaların büyük bir çoğunluğunda analizler için düzlem dalga açllım yöntemi (Sözüer 1991, Sakoda 2001) veya transfer matrisi yöntemi (Pendry ve MacKinnon 1992) kullanılmıştır. Düzlem dalga açlım yöntemi özdeğer denkleminin çözümüne dayalı olduğundan problem geometrisi karmaşıklaştıkça hesaplama yükü artmaktadır. FDTD yöntemi ile yapılan analizlerde ise, benzetim alanı (simulation domain) ağ örgüsünün (mesh) yoğunluğuna bağlı olarak daha doğru sonuç vermekte fakat hesap uzayını doğrusal olarak büyütmektedir (Kuang ve Kim, 2007). Bu yöntemlerin yanısıra transfer matrisi metodu (TMM), sonlu elemanlar metodu (FEM) (Qiu 2001) fotonik kristalin bant yapılarını hesaplamak için kullanılan metodlardan bazılarıdır. TMM sıklıkla tercih edilen bir yöntem olmasına rağmen tanımı gereği barındırdığı üstel fonksiyonların pozitif ve negatif argümanları sebebiyle kararsız sonuçlar üretebilmektedir. Öte yandan genelleştirilmiş saçılma matrisi (GSM) yöntemi sadece negatif argümanlı üstel fonksiyonlar içerdiğinden TMM yöntemine göre sayısal olarak kararlıdır. Geleneksel olarak özdeğer denkleminin çok sayıda parametre takımı için çözümünde genetik algoritma ve yapay sinir ağları gibi salt sayısal yöntemler de kullanılabilmektedir.
Alternatif olarak (Şimşek ve Topuz, 2007) yayınında ispatlandığı üzere kayıpsız birim hücrenin tek Floquet modlu bölge içerisinde yer alan iletim/durdurma bant geçiş frekansları saçılma parametreleri cinsinden elde edilen alternatif fonksiyonlar yardımıyla tespit edilebilmektedir. Bu yöntem AFGSM metodu olarak tasarım çalışmaları ile literatürde yer almaktadır (Erkan vd., 2018).

\section{Materyal ve Yöntem}

Problem tanımında periyodiklik ilişkisi kullanılarak bir boyutlu periyodik fotonik kristal yapıların dispersiyon (dağllma) denklemi dik geliş ve eğik geliș durumları için türetilerek matematiksel model ifade edilebilmektedir (Yariv, 2006). Geleneksel olarak durdurma bant aralıklarının tespiti özdeğer denkleminin çözülmesi ile sağlanmaktadır.

Literatürde belirtildiği üzere özdeğer (dispersiyon) denklemi

$$
\begin{aligned}
\operatorname{Cos}(K p)= & \operatorname{Cos}\left(k_{1}^{z} p_{1}\right) \operatorname{Cos}\left(k_{2}^{z} p_{2}\right) \\
& -M \operatorname{Sin}\left(k_{1}^{z} p_{1}\right) \operatorname{Sin}\left(k_{2}^{z} p_{2}\right)
\end{aligned}
$$

şeklinde ifade edilmektedir (Şimşek 2013) . Burada

$$
M=\left\{\begin{array}{c}
\frac{1}{2}\left(\frac{k_{2}^{z}}{k_{1}^{z}}+\frac{k_{1}^{z}}{k_{2}^{z}}\right) T E \\
\frac{1}{2}\left(\frac{n_{1}^{2} k_{2}^{z}}{n_{2}^{2} k_{1}^{z}}+\frac{n_{2}^{2} k_{1}^{z}}{n_{1}^{2} k_{2}^{z}}\right) T M
\end{array}\right.
$$

Eşitlik (1) ve (2)'de $\boldsymbol{k}_{1}^{z}$ ve $\boldsymbol{k}_{2}^{z}$ sirasiyla birinci ve ikinci ortamda dalga vektörünü, $\boldsymbol{p}_{1}$ ve $\boldsymbol{p}_{2}$ sırasıyla birinci ve ikinci dielektrik katmanın tabaka uzunluklarını, $\boldsymbol{p}$ bir periyotluk tabaka uzunluğunu, $\boldsymbol{n}_{1}$ ve $\boldsymbol{n}_{2}$ periyodik yapı kırılma indislerini temsil etmektedir. Dielektrik tabaka dalga vektörleri açısal frekans $\omega$, geliş açısı $\theta_{i}$ ve kırılma indisi $\boldsymbol{n}_{\boldsymbol{i}}$ cinsinden aşağıdaki gibi ifade edilmektedir.

$$
k_{i}^{z}=\frac{\omega n_{i}}{c} \cos \theta, k_{x}=\frac{\omega n_{i}}{c} \sin \theta, \quad i=1,2
$$

Dik geliş durumunda geliş açısı $\theta=0^{\circ}$ ve $\cos \theta=1, \sin \theta=0$ şeklindedir. Burada dalga vektörü bileşenleri $x$-yönünde sıfırdır. Eğik geliş durumunda ise geliş açısı $\theta \neq 0^{\circ}$ ve $\cos \theta \neq 1, \sin \theta \neq 0$ şeklindedir. Burada dalga vektörünün $x$-yönündeki bileșeni sıfırdan farklıdır ve sisteme katkısı bulunmaktadır. (1) no'lu dispersiyon dekleminde de bulunan $\boldsymbol{K}$ terimi Bloch dalga vektörünü temsil etmektedir. 


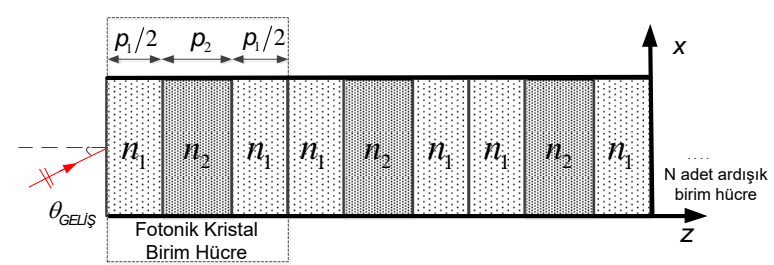

Şekil 1. Bir boyutlu fotonik kristal birim hücre geometrisi

Şekil 1'de verilen bir boyutlu simetrik periyodik yapının iki kapılı devre modeline göre sparametreleri eşitlik (4)'de verildiği gibi hesaplanmaktadır.

$$
\left[\begin{array}{l}
b_{1} \\
b_{2}
\end{array}\right]=\left[\begin{array}{ll}
S_{11} & S_{12} \\
S_{21} & S_{22}
\end{array}\right]\left[\begin{array}{l}
a_{1} \\
a_{2}
\end{array}\right]
$$

Denklem (4)'de $\boldsymbol{b}_{\boldsymbol{i}}$ ve $\boldsymbol{a}_{\boldsymbol{i}}$ birim hücreye gelen ve yansıyan dalgaları göstermektedir.

Floquet periyodikli koşulu ve sınır koşulları uygulanarak birim hücre özdeğer denklemi (5) elde edilmektedir.

$$
\left[\begin{array}{ll}
I & -S_{11} \\
0 & -S_{21}
\end{array}\right]\left[\begin{array}{c}
b^{(i)} \\
a^{(i)}
\end{array}\right]+\lambda\left[\begin{array}{ll}
-S_{12} & 0 \\
-S_{22} & I
\end{array}\right]\left[\begin{array}{c}
b^{(i)} \\
a^{(i)}
\end{array}\right]=0
$$

Özdeğer denklemini kökleri eşitlik (4)'de verildiği gibi alternatif olarak yazılabilmektedir.

$$
\cos (\theta)=\frac{1-S_{11}{ }^{2}+S_{21}{ }^{2}}{2 S_{21}}, \quad \theta=K p
$$

Simetrik birim hücre için bir Floquet modunun reaktif gücü birim hücrenin saçllma parametreleri cinsinden

$$
X_{ \pm}=\operatorname{Im}\left\{S_{11} \pm S_{21}\right\}
$$

olarak ifade edilebilir. Böylece AFGSM yönteminde band kenar frekansları tanımlanan $X_{+}$ve $X_{-}$ fonksiyonlarının sıfır geçişleri ile elde edilirler.

Fotonik Kristalin fotonik durdurma bandı çalışma frekansına, geliş açısına ve kutuplanmaya bağlı olarak değişmektedir. $\mathrm{Bu}$ sebeple problemin çözümünde TE (enine elektrik) ve TM (enine manyetik) modlar oluşmaktadır. Belli bir frekans bandında tüm geliş açıları ve her iki kutuplanma (TE veya TM) için oluşan fotonik durdurma bandı tümyönlü fotonik durdurma bandını (OBG) oluşturmaktadır. Örnek olarak kırılma indisi $\mathrm{n}_{1}=4.6$, $\mathrm{n}_{2}=1.6$ ve tabaka kalınlıkları $\mathrm{p}_{1}=48 \mathrm{~nm}, \mathrm{p}_{2}=155 \mathrm{~nm}$ seçilerek elde edilen yapının (bkz. Şekil 1) farklı geliş açları ve TE (enine elektrik), TM (enine manyetik) kutuplanmalar için verdiği durdurma bant aralıkları Şekil 2'de şematik olarak gösterilmiştir.

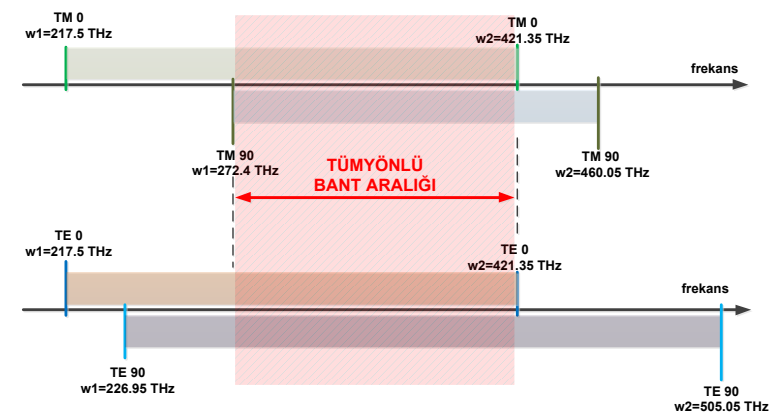

Şekil 2. Tümyönlü yansıtıcı bant aralığının frekans spektrumunda TE ve TM kutuplanma için gösterimi

Şekil 2'de TM kutuplanmasında elde edilen durdurma bant aralı̆̆ının TE kutuplanmasında elde edilen sonuçlara göre daha dar bant vermesi sebebiyle tümyönlü durdurma bant bölgesi için TM $0^{0}$ ve TM $90^{\circ}$ koşullarının kontrol edilmesinin yeterli olduğu gösterilmektedir. Şekil 3'te aynı yapının TM kutuplanmasında tüm geliş açıları için elde edilen bant aralıkları verilmiștir. Boyalı dikdörtgen alan $270 \mathrm{THz}-420 \mathrm{THz}$ bölgesinde tümyönlü durdurma bandını göstermektedir.

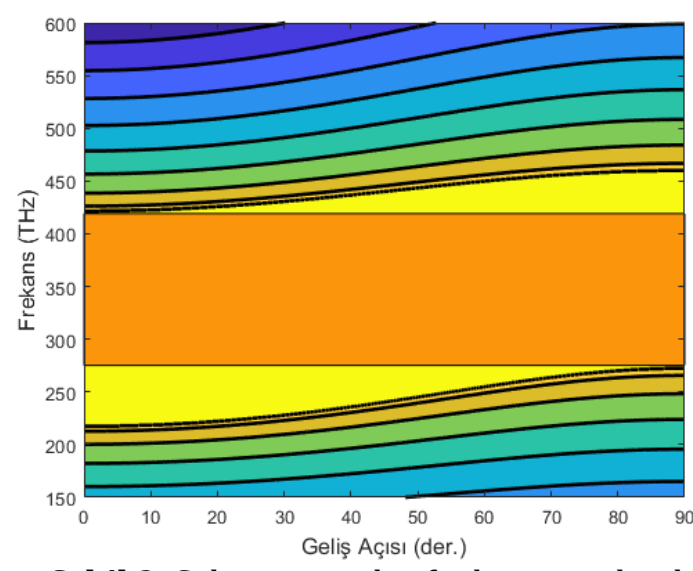

Şekil 3. Geliş açısının bir fonksiyonu olarak durdurma bant aralıkları (TM kutuplanma)

Literatürde tümyönlü yansıtıcı elde etmek için genellikle çeyrek-dalga tabaka (QWS) kalınlığı referans alınmaktadır. 4.bölümde tabaka kalınlıkları QWS uzunluğunda seçilmeden elde edilebilen geniş tümyönlü yansıtıcı tasarımı verilmiştir.

\section{Araştırma Bulguları}

Bir boyutlu fotonik kristal malzemeler periyodik veya yarı-periyodik olarak kaskad bağlanarak geniş durdurma bandı tasarımları yapılabilmektedir. Bu tasarım tek tip birim hücreden en geniş omnidireksiyonel bandın elde edilmesi veya farklı tipte malzeme kullanılarak elde edilen farklı birim hücrelerin kaskad bağlanarak tümyönlü band elde edilmesi şeklinde özetlenebilir. 


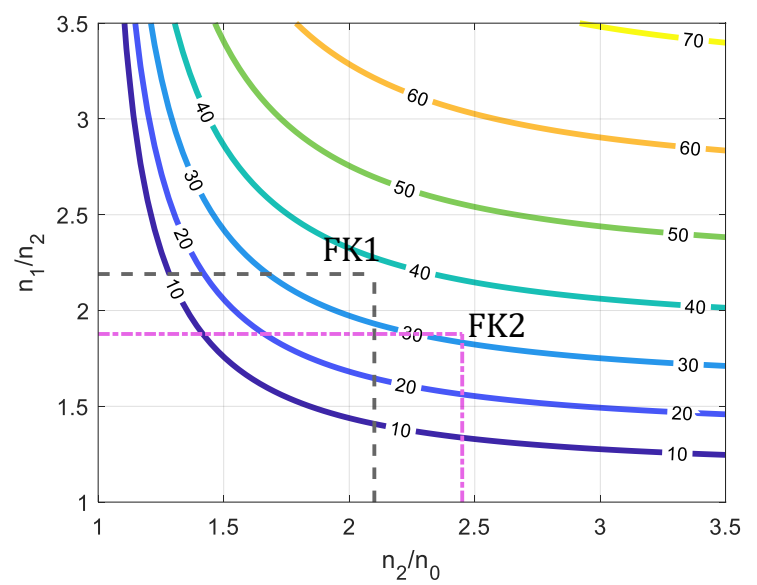

Şekil 4. Tümyönlü yansıtma bağıl bant genişliğinin merkez frekansa oranı kontür diyagramı

Tümyönlü yanıstıcının bantgenişliğinin seçilen dielektrik malzemelerin kırılma indisleri ile olan ilişkisi Şekil 4'de verilmiştir (Winn 1998). Tümyönlü yansıtıcı durdurma band genişliğinin merkez frekansına oranı tümyönlü bağıl bant genișliği (ORB: omnidirectional relative bandwidth) olarak adlandırılmaktadır. Işığın geliş ortamının kırılma indisi $n_{0}$, birinci ve ikinci tabakaların kırılma indisleri ise sırasıyla $n_{1}$ ve $n_{2}$ ile gösterilmektedir. Şekil 4'de eğrilerin üzerinde ORB oranları yüzdesel olarak verilmektedir. Örnek olarak iki farklı fotonik kristal için kırılma indisi çiftleri grafikten seçilmiştir.

Şekil 4'de kesikli çizgiler $\left(n_{1}=4.6\right.$ Tellurium, $n_{2}=2.1$ $\mathrm{Ta}_{2} \mathrm{O}_{5}$ ) birinci fotonik kristal (FK1) için seçilen kırılma indislerini, kesik-nokta çizgi ise $\left(n_{1}=4.6\right.$ Tellurium, $n_{2}=2.45 \mathrm{TiO}_{2}$ ) ikinci fotonik kristal (FK2) için seçilen kurılma indislerini göstermektedir. Her iki malzeme için de geliş ortamı hava $\left(n_{0}=1\right)$ kabul edilmiștir.AFGSM yöntemi kullanılarak tümyönlü yansıtıcıların TM $0^{0}$ ve TM $89^{0}$ için bant kenarları dalgaboyu cinsinden verilmektedir (Şekil 5). Kesikli çizgiler $X_{+}$fonksiyonunun, düz çizgiler ise $X$. fonksiyonunun sıfır geçişlerini temsil etmektedir. AFGSM fonksiyonları ile elde edilen bant kenar değerleri ve tümyönlü bağll bant genişliği (ORB) değerleri Tablo 1'de özet olarak verilmiştir. Birinci malzeme çifti (Tellurium ve $\mathrm{Ta}_{2} \mathrm{O}_{5}$ ) kullanılarak 416 nm'lik tümyönlü durdurma bandı; ikinci malzeme çifti (Tellurium ve $\mathrm{TiO}_{2}$ ) kullanarak ise $321 \mathrm{~nm}$ 'lik durdurma bandı elde edilmiştir. $\mathrm{Bu}$ değerler sırasıyla \% 28.76 ve \% 29.58'lik tümyönlü bağll bant genişliği değerlerine karşıllık gelmektedir.

Tablo 1. Seçilen fotonik kristal malzeme çiftleri kırılma indisi ve durdurma bant aralıkları

\begin{tabular}{|c|c|c|c|c|c|c|}
\hline & $\begin{array}{c}\mathbf{p 1} \\
(\mathrm{nm})\end{array}$ & $\begin{array}{c}\mathbf{p 2} \\
(\mathrm{nm})\end{array}$ & $\begin{array}{c}\text { TM 0 } \\
(\mathrm{nm})\end{array}$ & $\begin{array}{c}\text { TM 890 } \\
(\mathrm{nm})\end{array}$ & $\begin{array}{c}\text { OBG } \\
(\mathrm{nm})\end{array}$ & $\begin{array}{c}\text { ORB } \\
(\%)\end{array}$ \\
\hline FK1 & 112.8 & 96.8 & $\mathbf{1 2 3 8 . 2}-1821$ & $1205.2-\mathbf{1 6 5 4 . 9}$ & 416 & 28.76 \\
\hline FK2 & 48.8 & 132 & $\mathbf{9 2 4 . 6}-1357$ & $879.6-\mathbf{1 2 4 5 . 6}$ & 321 & 29.58 \\
\hline
\end{tabular}

Tasarlanan tümyönlü yansitıcıların durdurma bant aralıkları PWE yöntemi ile hesaplanarak frekans ekseninde çizdirilmiştir (Şekil 6). Şekilde bulunan kırmızı çizgiler ışık çizgisini, sarı boyalı alan ise tümyönlü yansıtıcıllk bölgesini göstermektedir.

Ortadaki eksen grafiği ikiye ayırarak sol taraf için TM kutuplanma sağ taraf için ise TE kutuplanma bant eğrilerini temsil etmektedir.
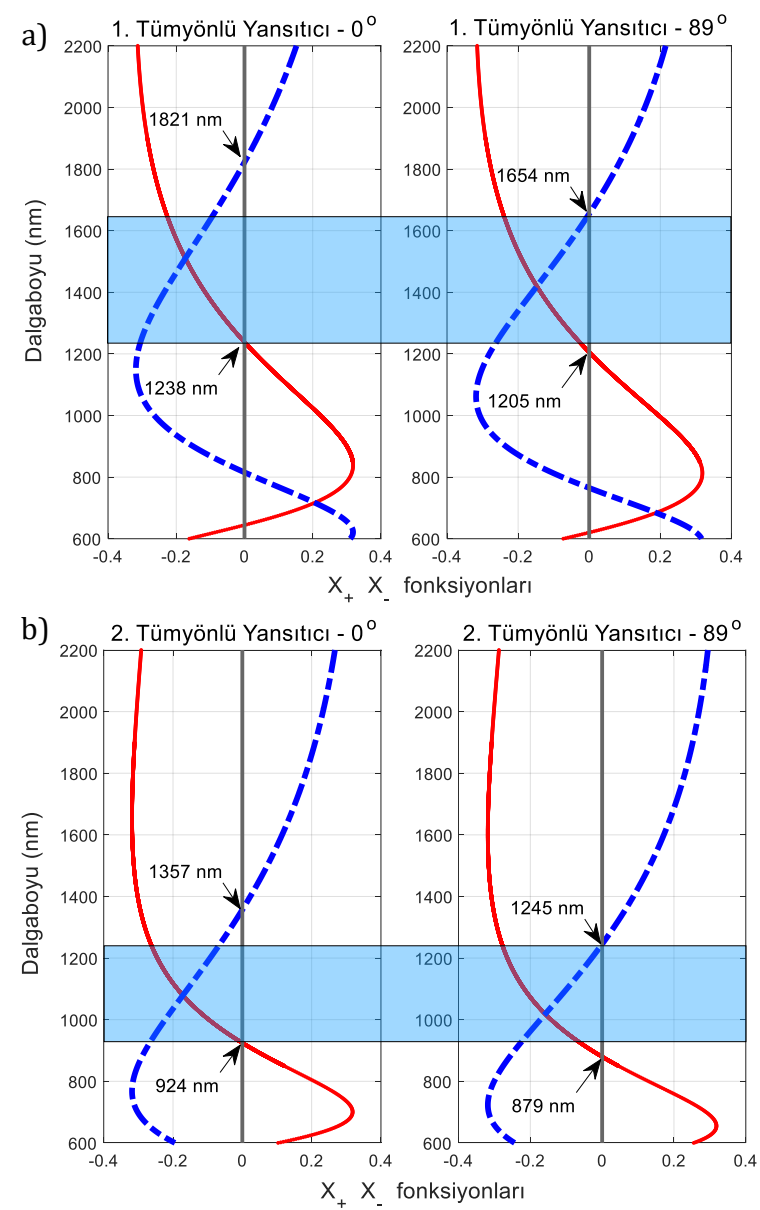

Şekil 5. AFGSM yöntemi kullanılarak birinci ve ikinci tümyönlü yansıtıcı için band kenar frekanslarının kestirilmesi a) FK1 b) FK2 

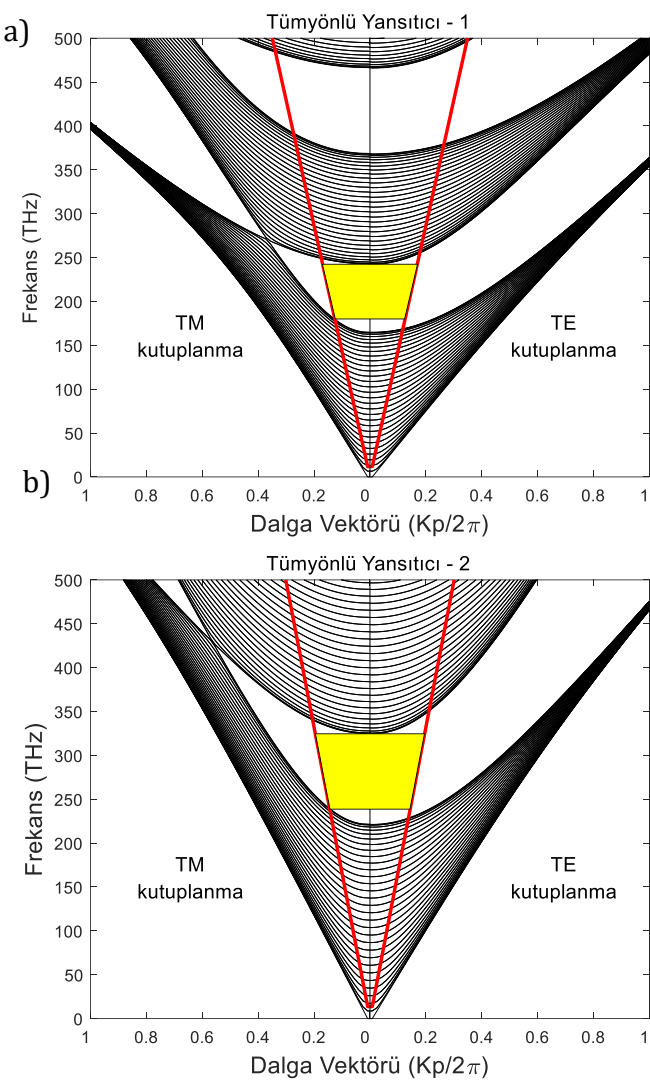

Şekil 6. PWE yöntem ile elde edilen tüm yönlü yansıtıcı bant eğrileri a) FK1 b) FK2

Birinci tümyönlü yansıtıcı için boyalı alanın üst sınırı $242.4 \mathrm{THz}(1238 \mathrm{~nm})$, alt sinırı ise $181.2 \mathrm{THz}(1655$ $\mathrm{nm}$ ) band kenar değerlerini;

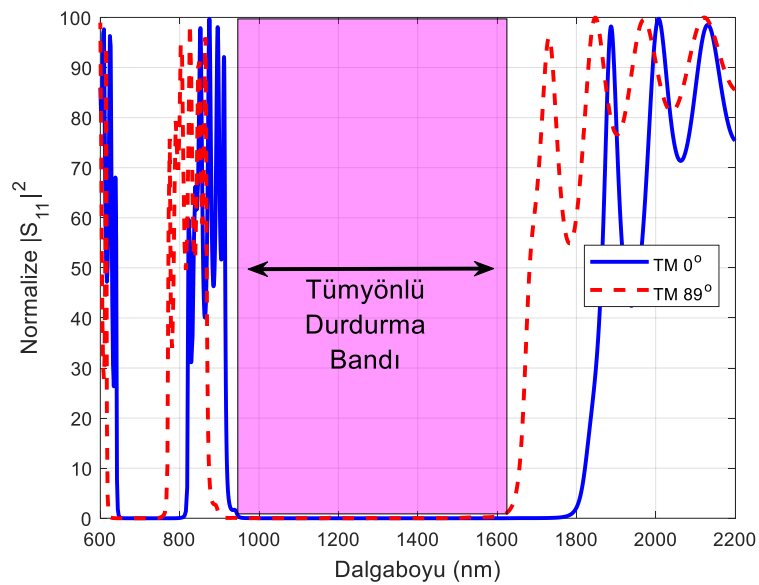

Şekil 7. FK1 ve FK2 yapılarının kuple edilmesi ile elde edilen geniş bantlı tümyönlü yansıtıcının durdurma bant bölgesi

ikinci tümyönlü yansıtıcı için boyalı alanın üst sınırı 324.6 THz (924 nm), alt sinırı ise 238.7 THz (1256 $\mathrm{nm}$ ) band kenar değerlerini vererek AFGSM yöntemi ile PWE arasındaki doğruluğu oraya koymaktadır. Çalışmanın devamında FK1 ve FK2 yapıları birbirine kuple edilerek geniş bantlı tümyönlü yansıtıcı tasarlanmıştır. Elde edilen tümyönlü yansıtıcının durdurma bant genişliği böylece 737 nm'ye ORB değeri ise \% 56.63'e yükselmiştir (Şekil 7).

\section{Sonuç ve Tartışma}

Yapılan çalışmada, iki farklı fotonik kristal yapı kuple edilerek geniş bantlı tümyönlü yansıtıcı tasarımı gerçekleştirilmiştir. Nanometre boyutlarında tasarlanan bu bileșenlerin optik frekans spektrumunda filtre, mikrokavite, hareketli mikro aynaların kullanıldığı optiksel çapraz bağlayıcılar ve optik fiberler gibi çeşitli uygulama alanı bulunmaktadır. Özellikle telekomünikasyon haberleşme sistemlerinde elektronik - optik dönüşümü yapmaya gerek kalmadan sinyalin optik olarak taşınması ve anahtarlama işleminin entegre optik anahtarlama modülleri ile yapılabilmesi yüksek band genişliklerinde veri iletimini mümkün kılmaktadır. $\mathrm{Bu}$ çalışmada uygulanan yöntem ile fotonik kristallerin tümyönlü yanısıtıcı uygulamalarında istenen frekans bandında amaca uygun olarak tasarlanabileceği gösterilmiştir.

Elde edilen tümyönlü yansıtıcının durdurma bant aralığı 924 nm - 1654 nm olup literatürde Kim'in (2002) çalışmasında yer alan sonuçlara (342.4 nm, $1286.8 \mathrm{~nm}$ ile $1629.1 \mathrm{~nm}$ arasında) göre \%115 daha geniş band aralığı elde edilmiştir. Bilinen diğer yöntemlere kıyasla AFGSM bant kenarlarını hesaplamak için hızlı bir alternatif yaklaşım olduğundan tabaka kalınlıklarını yüksek hassasiyet ile tarayarak tasarım yapmak mümkündür. AFGSM yönteminin süre avantajını vurgulamak adına yapılan ön çalışmalarda 20 hücreli bir boyutlu fotonik kristalin PWE ile TE kutuplanmasında analizi 53.6 sn, TM kutuplanmasında analizi 111.7 sn de tamamlanırken AFGSM ile analizi 0.04 sn sürmüștür. Aynı problem için sonlu elemanlar metodu (FEM) yöntemi ile çalışan ticari yazılım CST'ye göre 103 kat daha hızlı sonuç vermiştir.

Tasarım aşamasında kullanılacak olan ters problem çözümü için yapılan ön incelemede yine FEM yöntemi kullanan ticari yazılım HFSS ile aynı fotonik kristalli problemin analizi sadece bir polarizasyon için yaklaşık $13 \mathrm{dk}$. sürerken AFGSM yöntemi ile bu analiz 0,05 sn. sürmüştür (ters problem için amaç fonksiyonunda istenen frekans aralığında, dielektrik tabakaların kırılma indisinin bilindiği, tabakalardan birinin kalınlığı bilinirken diğerinin bilinmediği ve 5 adımda belirli bir aralıkta süpürülerek hesaplama yapıldığı göz önüne alınmıştır). Fotonik kristalin üretim aşamasında yüksek hassasiyette olası tüm parametrelerdeki değișim aralıkları göz önününe alınması gerekmektedir. $\mathrm{Bu}$ durumda 0,01 hassasiyet ile her iki katman için uzunlukların süpürülmesi $\left(\mathrm{x}^{4} 0^{4}\right)$, her iki kutupluluk tipinin incelenmesi (x2) ve geliş açısının 50 parçada taranması (x50) kat ișlem yükü olup toplamda $10^{6}$ işlem yükü oluşturacaktır. Bu durumda tasarım aşamasında $10^{6}$ işlem yükü barındıran bir problem için tasarım süresi HFSS ile 1800 gün, önerilen özgün yöntem ile 0,6 gün sürecektir. Bu açıdan çalışmada kullanılan AFGSM yönteminin fotonik kristalli optik 
bileşenlerin tasarım aşamasındaki yüksek hassasiyetli modellemelerde önemli katkı sağlayacağı düşünülmektedir.

\section{Conflict of Interest / Çıkar Catışması}

Yazarlar tarafından herhangi bir çıkar çatışması beyan edilmemiştir.

No conflict of interest was declared by the authors.

\section{Kaynaklar}

Banaei, H. A., \& Rostami, A. (2008). A novel proposal for passive all-optical demultiplexer for DWDM systems using 2-D photonic crystals. Journal of Electromagnetic Waves and Applications, 22(4), 471-482.

Erkan, O., Akıncı, M. N., \& Şimşek, S. (2018). A fast hybrid method for the bandgap analysis of 2D photonic crystals based on EMT and AFGSM methods. AEU-International Journal of Electronics and Communications, 87, 107-112.

Joannopoulos, J. D., Johnson, S. G., Winn, J. N., \& Meade, R. D. (2011). Photonic crystals: molding the flow of light. Princeton university press.

Kim, S. H., \& Hwangbo, C. K. (2002). Design of omnidirectional high reflectors with quarterwave dielectric stacks for optical telecommunication bands. Applied Optics, 41(16), 3187-3192.

Kuang, W., Kim, W. J., \& O'Brien, J. D. (2007). Finitedifference time domain method for nonorthogonal unit-cell two-dimensional photonic crystals. Journal of Lightwave Technology, 25(9), 2612-2617.

Liang, J., \& Yang, H. D. (2009). Microstrip patch antennas on tunable electromagnetic band-gap substrates. IEEE transactions on antennas and propagation, 57(6), 1612-1617.

Notomi, M., Shinya, A., Mitsugi, S., Kira, G., Kuramochi, E., \& Tanabe, T. (2005). Optical bistable switching action of Si high-Q photoniccrystal nanocavities. Optics Express, 13(7), 26782687.

Pendry, J. B., \& MacKinnon, A. (1992). Calculation of photon dispersion relations. Physical Review Letters, 69(19), 2772.

Prather, D. W., Shi, S., Sharkawy, A., Murakowski, J., \& Schneider, G. J. (2009). Photonic crystals. Theory, Aplications and Fabrication.

Qiu, M. (2001). Analysis of guided modes in photonic crystal fibers using the finite-difference time- domain method. Microwave and Optical Technology Letters, 30(5), 327-330.

Sakoda, K., \& Ochiai, T. (2001). Dispersion relation and optical transmittance of a hexagonal photonic crystal slab. Physical review B, 63(12), 125107.

Sharma, A., Dwivedi, V. K., \& Singh, G. (2008, July). $\mathrm{THz}$ rectangular patch microstrip antenna design using photonic crystal as substrate. In Progress in Electromagnetic Research Symposium, Cambridge, USA (pp. 161-165).

Simsek, S., \& Topuz, E. (2007). Some properties of generalized scattering matrix representations for metallic waveguides with periodic dielectric loading. IEEE Transactions on Microwave Theory and Techniques, 55(11), 2336.

Sözüer, H. S., Haus, J. W., \& Inguva, R. (1992). Photonic bands: Convergence problems with the plane-wave method. Physical Review B, 45(24), 13962.

Şimșek, S. (2013). A novel method for designing one dimensional photonic crystals with given bandgap characteristics. AEU-International Journal of Electronics and Communications, 67(10), 827-832.

Wosinski, L., Liu, L., Zhu, N., \& Thylen, L. (2009). Technology challenges for monolithically integrated waveguide demultiplexers. Chinese Optics Letters, 7(4), 315-318. 